\title{
Electron and ionic transport in high-radioactive silicate alkali-earth glasses
}

\author{
O.Zhydkov \\ Institute for NPP Safety Problems \\ of the National Academy of Sciences of Ukraine, \\ Kirova 36A, 07270, Chornobyl, Ukraine
}

Received August 16, 2004, in final form August 20, 2004

The paper is devoted to the experimental study of electric transport in a very special substance, namely alkali-earth glasses containing the noticeable quantity (up to $10 \%$ ) of dissolved irradiated uranium nuclear fuel and its fission and daughter products as well. Such a high-radioactive product was formed at the active stage of the well-known heavy nuclear accident which occurred on Chornobyl NPP facility in 1986. The soft matter behaviour was established by measuring the temperature dependence of viscosity, where the glassy properties had been identified unambiguously. Static electric conductivity temperature dependence was measured for $80 \mathrm{~K}-1000 \mathrm{~K}$ temperature interval. The transport processes connected with thermal activation of electrons, hopping conductivity in the band tails and variable range hopping $(\mathrm{VRH})$ were identified. The band structure of such glasses manifests the energy gap of 1.8-2.0 eV width, which formed due to long-range order and wide band tails connected with horizontal disorder, which, in its turn, may originate from numerous traps and internal radiation damages. The latter makes it possible to identify the investigated matter as devitrified glass. The distinguishing feature of such devitrified glasses is low ionization energy for electrons, providing a high spatial density of electron excitations in $\alpha$-particle tracks, which leads to such a collective phenomena as the so-called Coulomb explosion.

Key words: glass ceramics, radioactive glass, hopping conductivity

PACS: 72.20.Ee, 71.20.Dg

\section{Introduction}

The paper is devoted to the experimental study of electric transport in very special complicated substance. Such a matter has been formed as a product of wellknown heavy nuclear accident, which was occurred on Chornobyl NPP facility in 1986. Its formation occurred at the active stage of the accident by dissolving the 
uranium nuclear fuel and other constructive materials of reactor core in melted serpentine $\left(\mathrm{Mg}_{6}(\mathrm{OH})_{8} \times\left[\mathrm{Si}_{4} \mathrm{O}_{10}\right]\right)$; the latter had been used in the reactor construction as a heat-insulating filling. The irradiated fuel heat release served as a heat source for the melting process. The final product of melting process is known as LFCM lava-like fuel-containing material. There are several sorts of such materials, which vary in colour and in uranium content. The most widespread and typical LFCM sort is the so-called brown LFCM.

The averaged element composition for brown LFCM [1] is given below in the table 1.

Table 1. Element composition (significant quantities) of brown LFCM (mass \%).

\begin{tabular}{|l|l|l|l|l|l|l|l|l|l|}
\hline Element & Al & Mn & Fe & Mg & Si & Ca & $\mathbf{Z r}$ & Na & U \\
\hline Average & $3.5 \pm$ & $0.52 \pm$ & $0.84 \pm$ & $4 \pm$ & $30 \pm$ & $4.7 \pm$ & $4.8 \pm$ & $4 \pm$ & $8.4 \pm$ \\
Content & 0.7 & 0.2 & 0.2 & 0.9 & 3.6 & 0.8 & 1.1 & 0.4 & 0.2 \\
\hline
\end{tabular}

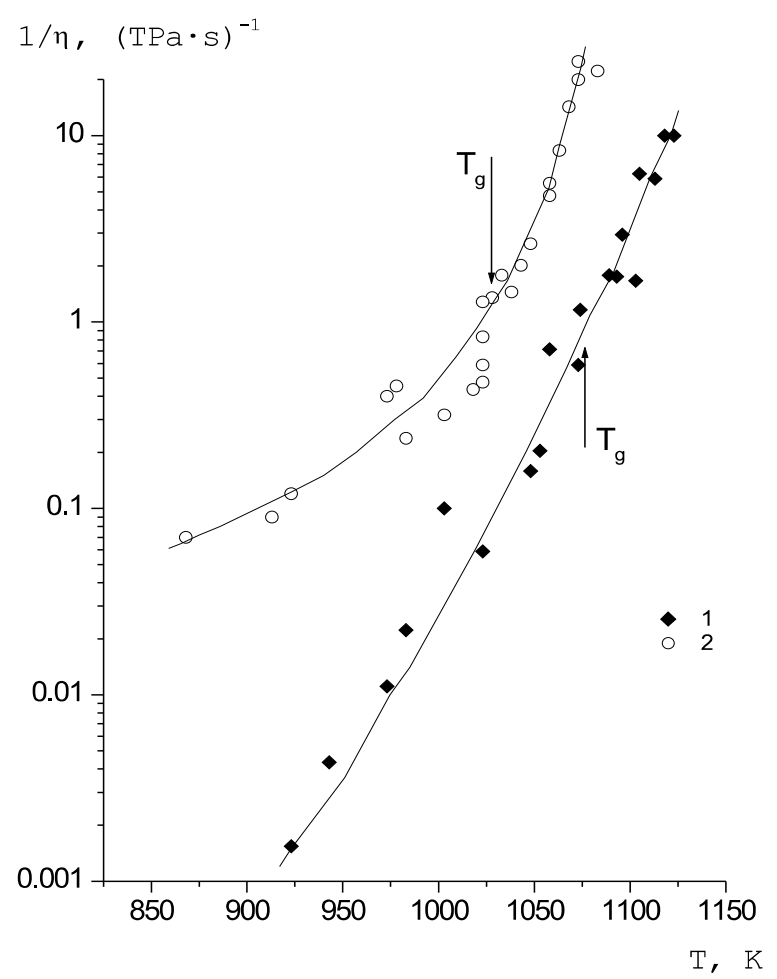

Figure 1. LFCM dynamic fluidity vs temperature dependences. 1 - the so-called multicoloured LFCM, 2 - brown LFCM. Vitrification temperature $\mathrm{T}_{g}$ corresponds to conventional viscosity value of $1 \mathrm{TPa} \cdot \mathrm{s}$.

The direct study of LFCM structure by routine X-ray analysis gives ambiguous results, as far as LFCM themselves are the powerful sources of X-ray radiation, which provides a strong background for detectors. In order to classify at least a condensed matter type (crystalline or amorphous), a temperature dependence of fluidity was measured. Corresponding results are presented in figure 1. 
From figure 1 one can easily identify the absence of a certain melting point for LFCM, but monotonic (and close to exponential) growth of LFCM fluidity with temperature. Such behaviour is typical of glasses (or glass ceramics). There are a few theories for viscous flowing of glasses, but all of them are based on the picture of presence of separate moving particles (called kinetic units), which provide flowing [2]. Viscosity itself is a statistical parameter, as far as its value is determined by the whole ensemble behaviour of interacting kinetic particles. Proper calculations for such ensemble behaviour will lead to the expression describing $\eta(\mathrm{T})$ behaviour as

$$
\eta(T)=\eta_{0} \exp \left(U_{a} / k T\right)
$$

where $\mathrm{U}_{a}$ is the activation energy for viscosity. Proper figure 1 data processing indicates that for the so-called multicoloured LFCM $\mathrm{U}_{a} \approx 3 \mathrm{eV}$; this is because we can find (low temperature) $\mathrm{U}_{a} \approx 1 \mathrm{eV}$ for brown LFCM. Those initial data enable us to estimate ion diffusion coefficients for LFCM at a room temperature as well as high-temperature LFCM fluidity.

One can identify from the above that LFCM vitrifiability is based mainly on $\mathrm{SiO}_{2}$ and partially on $\mathrm{Al}_{2} \mathrm{O}_{3}$ oxides (see table 1 ). LFCM belongs to a class of alkali silicate glasses regarding the noticeable $\mathrm{Na}^{+}$quantity, which, as it is known [2], enlarges the ion transport in glasses to a great extent. On the other hand, alkali-earth $\mathrm{Ca}^{++}$and $\mathrm{Mg}^{++}$ions are capable of blocking the ion mobility by way of saturating broken valence bounds [2].

Thus, the LFCM are alkali-earth silicate glasses, in which electric transport mechanisms are unclear. The latter, however, is important regarding high radioactivity of LFCM and simultaneous action of high internal electric fields and radiation damages on their behaviour.

As one can see, LFCM contain about $8 \%$ of uranium irradiated fuel, and, hence, its fission and transuranium daughter products. The internal radioactivity of glasses is provided by the fission products $\left(\mathrm{Cs}^{137}, \mathrm{Sr}^{90}\right)$ and daughter products of irradiated uranium $\left(\mathrm{Pu}^{239}, \mathrm{Am}^{241}\right)$. The specific $\alpha$-activity of such glasses is $10 \mathrm{MBq} / \mathrm{cm}^{3}$ (the typical value); $\beta$-activity can achieve $1 \mathrm{GBq} / \mathrm{cm}^{3}$ value.

The electric transport properties of such a matter present a scientific interest as far as it is a multi-phase heterogeneous non-equilibrium system, where a continuous generation of extra electrons ( $\beta$-particles) occurs. There is, however, the practical aspect: internal self-sustained currents cause a high inner electric field, especially just beneath the surface of material; those electric fields can indirectly stimulate the action of various factors leading to such a material self-destruction. The items, connected with the matter durable stability are of a crucial practical importance, regarding the large quantity (about 1000 tons) of such high-radioactive material, which now cannot be isolated from the environment in a sufficiently reliable way.

\section{Self-sustained currents and internal electric fields in LFCM}

It is quite clear that a certain part of $\beta$-electrons will escape an LFCM volume trough the surface and will provide an electric current density $J=e \cdot \Phi$, where $\Phi$ 
is the surface density of electron flow. One may expect a relatively large current value, taking into account a large quantity of secondary electrons, which are to be originated by each $\beta$-electron having typical initial energy of $200-1000 \mathrm{keV}$. Actually, the volume concentration of moving particles $\mathrm{N}$ will provide their flow density (in [3] it was calculated for $\alpha$-particles)

$$
\Phi=N \frac{\lambda}{4}
$$

where $\lambda$ is a whole path of particles in condensed media. The $\mathrm{N}$ quantity should exceed the one calculated from specific radioactivity and hence the current density $J$ by two-three orders, as far as $J$ does not depend on the energy of electrons escaping the surface. There was provided a special workbench experiment devoted to direct measurement of electric current provided by electrons escaping LFCM surface. At the same time the possibility was provided to quantitatively identify the low-energy electron spectrum by applying a stopping potential to the anode (the LFCM specimen surface served as a cathode). The corresponding volt-ampere characteristic is indicated in figure 2.

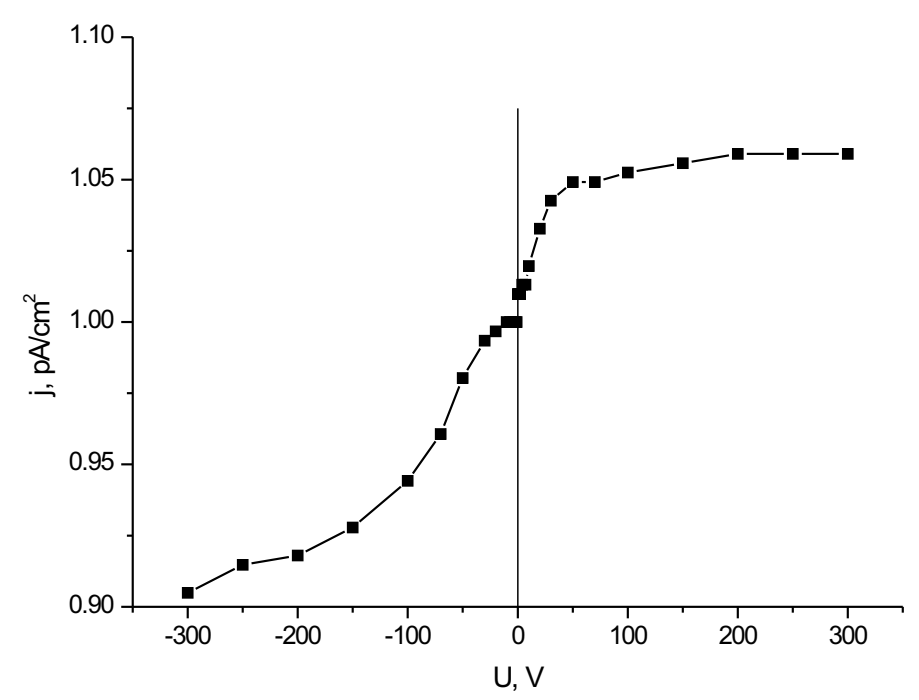

Figure 2. Density of current emitted by LFCM surface in vacuum $(0.001 \mathrm{~Pa})$ on the stopping potential dependence.

One can see in figure 2 that there are no expected low-energy electrons input in total electric current as far as the curve indicates a weak $J(U)$ dependence only. Moreover, a thorough qualitative analysis of this curve behaviour for $U<0$ region (stopping external field) indicates that there are no electrons of $E<50 \mathrm{eV}$ energy and the input of electrons belonging to $300 \mathrm{eV}<E<50 \mathrm{eV}$ energy interval (at $U \approx 300 \mathrm{~V}$ there is a full stopping for low-energy electrons since the curve derivative is close to zero) does not exceed $3-4 \%$. The current density value corresponds to the 
one estimated from (2) if $N$ corresponds to the known (mentioned in Introduction) specific $\beta$-activity and there is no need to take a large quantity of secondary electrons into account. Observable picture seems contradicting at first glance. The phenomenon under observation, however, has a simple physical explanation based on the consideration that $\lambda$ parameter in (2) itself depends on $E$ to a great extent. Such a situation was analysed in detail in [4], where based on the tabulated data [5] it was identified that $\lambda(E)$ function sharply decays with the electron energy decreasing. The latter is the main reason for a negligibly small input of low-energy electrons in the total $\Phi$ value, despite their doubtlessly high concentration just beneath the surface. The energy spectrum of the emitted electrons was experimentally estimated in [4], where it was found that it mainly corresponds to a $\beta$-spectrum of Cs-137 and Sr-90 [6], which provide a main $\beta$-activity in LFCM volume. Thus, one may conclude that, on the one hand, there is a certain surface Coulomb barrier located just beneath the surface, which is non-transparent for low-energy electrons. On the other hand, there is an electron-lacking region, which formed at the depth $\lambda(0.1-0.2 \mathrm{~mm}$ for majority of $\beta$-electrons) under the surface. The above resulted in the stationary (in a long-time scale) under-surface electron flow directed from LFCM surface within its volume up to the a depth of the order of $\lambda$. As it will be clear hereinafter, such a stationary picture can exist only at a room (and lower) temperature, when there are no free electrons, but electric conductivity can be realized through localized states by hopping mechanisms.

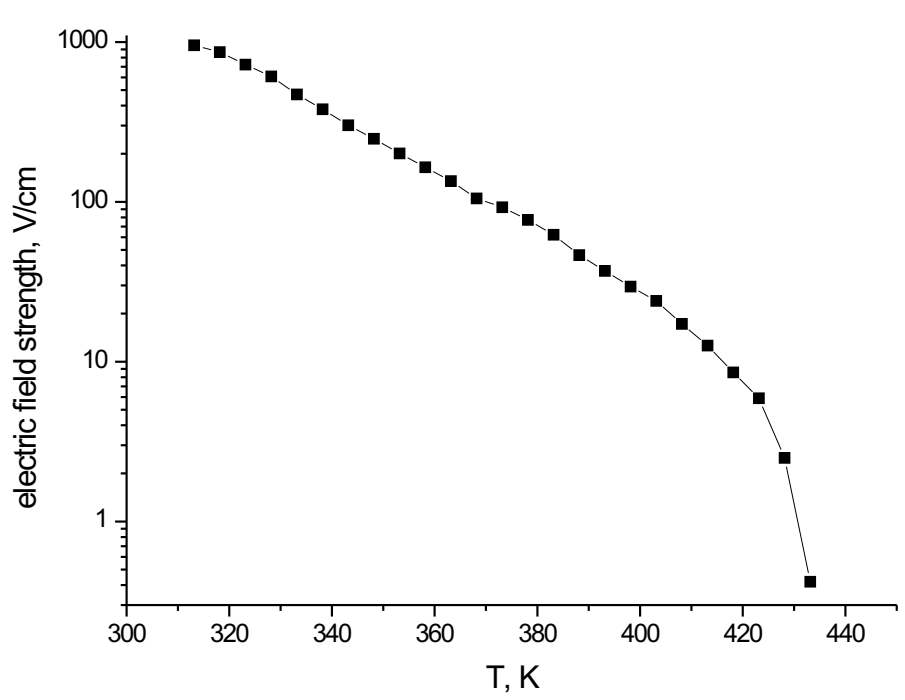

Figure 3. Temperature dependence of self-sustained electric field generated by brown LFCM specimen.

It is quite clear from the above that noticeable hopping conductivity can exist when there is a large density of localized states (traps for electrons) only, which can be provided by initial structure defects or by radiation damages. As far as hopping 
parameters (and possible free electron concentration) do depend on temperature to a large extent, the temperature increase will lead to a redistribution of internal electric fields and currents. The results of some pertinent experiments are presented below.

One of the experiments was devoted to the measuring of spontaneously generated electric field. There was used the plane specimen, the thickness of which $(1 \mathrm{~mm})$ was taken larger than $\lambda$. The potential difference was measured with high-impedance voltmeter. Corresponding temperature dependence is presented in figure 3 .

One can see in figure 3 that spontaneous electric field strength exceeds $1 \mathrm{kV} / \mathrm{cm}$ and decays exponentially (with activation energy about $0.43 \mathrm{eV}$ ) while temperature increases. The given electric field strength should be understood as an average integral value for the whole thickness, but the possible local value for the near-surface spatial region is still unclear. Sharp decay may be connected with the following two processes: (a) the release of the localized electron from the existing traps and (b) sharp increase of volume conductivity due to free electron generation by way of their thermal activation on the mobility edge. Both processes will lead to the elimination of the above mentioned surface Coulomb barrier and to the increase of self-sustained current. There was provided a special experiment on self-sustained current in shortcircuit regime measurement. Current versus temperature dependences are reflected in figure 4.

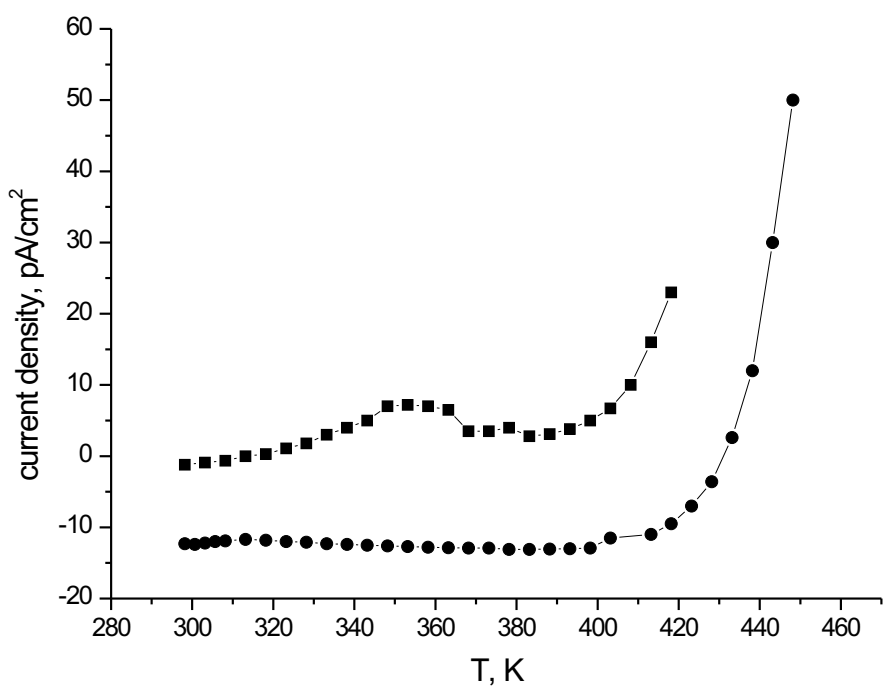

Figure 4. Measured short-circuit regime self-sustained electric current on temperature dependences. Zero level is a conventional quantity. Lower curve corresponds to a very slow heating. Upper curve was measured three days later and corresponds to the heating velocity of $0.025 \mathrm{~K} / \mathrm{s}$.

One can observe in figure 4 (the lower curve) the sharp increase of current at $T>400 \mathrm{~K}$, though it is clear that current originates from nuclear processes, which 
cannot depend on temperature. Possible physical explanation for the observed phenomenon is the appearance of thermally activated electrons, which break the surface Coulomb barrier and in this way make possible a large quantity of secondary electrons into the electric transport involvement. Data analysis indicates that thermal activation energy for such a process is about $1 \mathrm{eV}$, which, as it will be clear hereinafter, corresponds to the energy for electric conductivity in high-temperature region. The LFCM specimen was kept at a room temperature for a few days in order to fill in high-energy traps, if any. Here, a method was used accepted for semiconductors having high concentration of deep impurities, where relatively quick heating leads to liberation of electrons from traps and, hence, to the appearance of thermalstimulated current [7]. The result of such an experiment is reflected by the upper curve in figure 4 . It is not difficult to identify the thermal peak at $355 \mathrm{~K}$ vicinity. Data processing in a manner described in [7] indicates the presence of the traps of $0.4 \sim \mathrm{eV}$ depths. The nature of the trap is unclear yet. The current lowering just after $370 \mathrm{~K}$ indicates that the traps are already exhausted at that temperature.

\section{Electric transport in LFCM volume}

It is clear from the above that to identify the physical mechanisms, responsible for electric transport in LFCM, is a difficult task. Self-sustained currents and spontaneous electric fields will not permit to provide the conductivity measurements in a standard way. The correct way in this situation is to measure volt-ampere characteristic at every temperature point and then to find its derivative, when electric field is close to zero. A heap of such a derivative values will provide a temperature dependence of low-field (ohmic) electric conductivity. There was provided the special investigation for LFCM specific resistance on temperature dependence, where a $80 \mathrm{~K}<T<1000 \mathrm{~K}$ temperature region has been covered. The temperature dependence of LFCM specific resistance (high temperature region) is indicated in figure 5 .

One can see in this figure that (at $T>350 \mathrm{~K}$ ) such a dependence can be satisfactoryly described in a form of a simple activation law, namely as

$$
\rho(T)=\rho_{0} \exp \left(E_{1} / k T\right),
$$

where $\mathrm{E}_{1}$ is the corresponding activation energy and $\rho_{0}$ is the pre-exponent coefficient. As it was mentioned earlier, there are two possible mechanisms for electric transport. In principle, the first one may be connected with ionic hopping conductivity, where an ion hopping is thermally activated. A simple evidence in favour of such a mechanism may be an observable additional hopping stimulated by electric field; those can be identified as the rise of hopping conductivity with external electric field increasing even at moderate electric field values. In order to testify the above, the volt-ampere characteristic of LFCM specimen at $\mathrm{T}=550 \mathrm{~K}$ is performed in figure 6 .

One can see in this figure the high linearity of the characteristic up to external electric field strength $\approx 1.5 \mathrm{kV} / \mathrm{cm}$, which permits to identify the non-hopping 


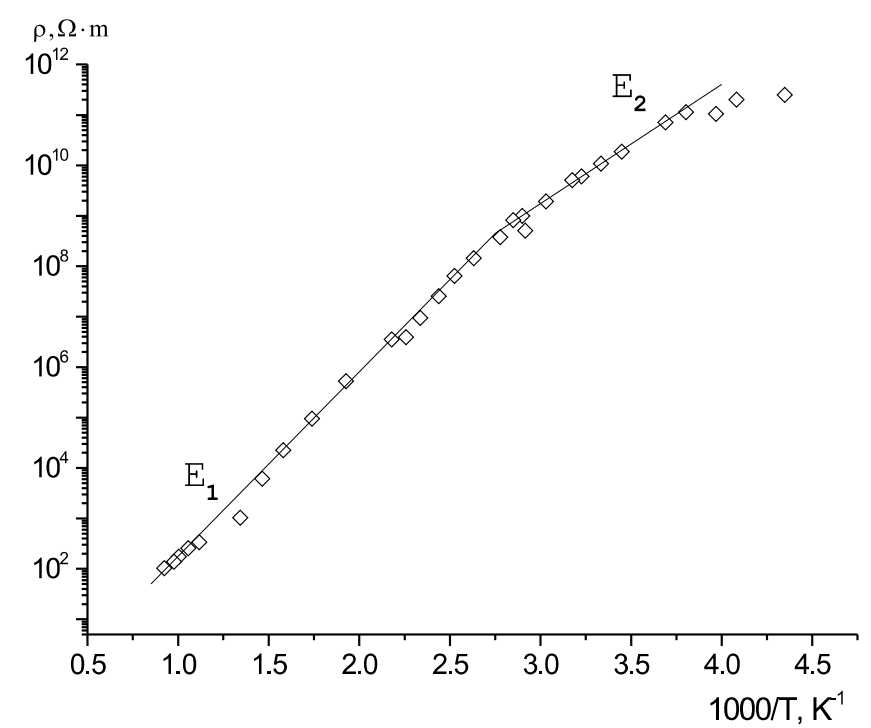

Figure 5. Dependence of brown LFCM specific resistance on reciprocal temperature. Both $E_{1}$ and $E_{2}$ activation energies can be found from the slope.

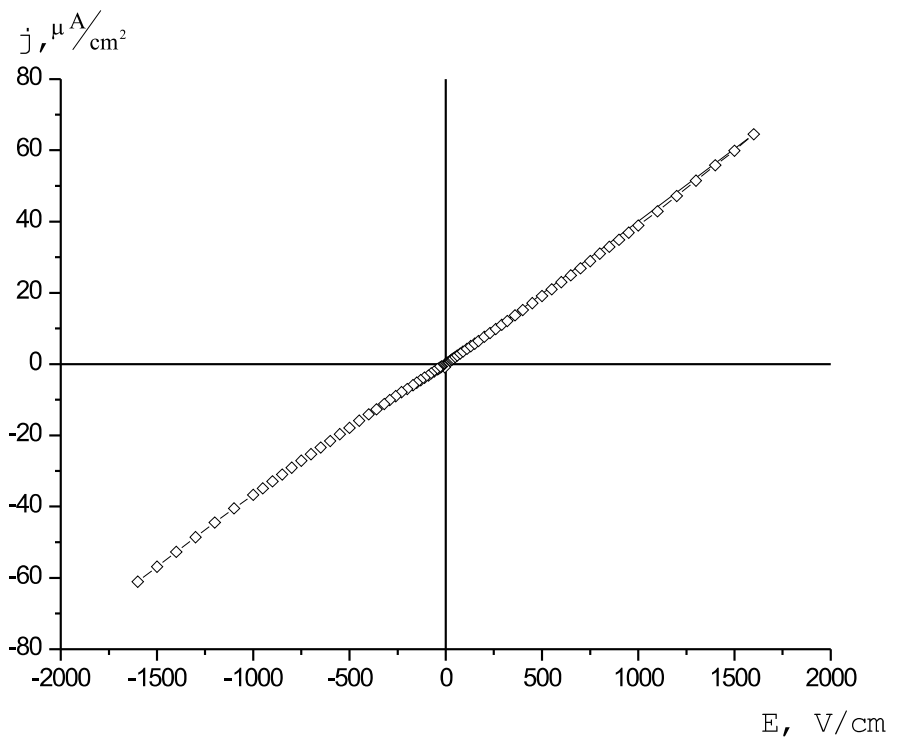

Figure 6. LFCM volt-ampere characteristic at $T \approx 550 \mathrm{~K}$. Specific conductivity can be found from its slope. 
mechanism of electric transport at this temperature range. One cannot exclude, however, a certain input of ionic hopping in high-temperature conductivity; it is known that in homology (composition) raw of complicated silicate glasses where ionic hopping mechanism changes by thermal-activated electron conductivity, nobody can identify for sure the noticeable activation energy changes [2]. Besides this, the high volt-ampere characteristic linearity in principle may be connected with the small hopping range for ions and, therefore, non-linearity can be manifested at extremely high electric fields only. Another possible mechanism is a thermal activation of electrons from a Fermi level into the states lying beyond a mobility edge $[2,8]$. Such a mechanism is typical of semiconductor glasses, where alkali ions (such as $\mathrm{K}^{+}$, $\mathrm{Na}^{+}$or $\mathrm{Li}^{+}$) are absent, or ionic hopping mechanism is suppressed by two-valence alkali-earth ions, such as $\mathrm{Ca}^{++}, \mathrm{Mg}^{++}$or $\mathrm{Ba}^{++}$. As it was mentioned in Introduction, in our system such a suppression is doubtlessly connected with noticeable $\mathrm{Ca}$ and $\mathrm{Mg}$ content (see also table 1). The additional argument in favour of non-hopping mechanism of electric transport (in a given temperature range) is the absence of noticeable frequency dispersion of conductivity up to $1 \mathrm{kHz}$ frequency. Determined from $(3)$ activation energy $E_{1} \approx 0.74 \mathrm{eV}$ value corresponds to the energy distance between the Fermi level and the mobility threshold, which, in its turn, corresponds to a percolation level in a conduction band. The conduction band existence, as it is known, is possible due to short-range order and valence bounds between neighbouring atoms coordination. As far as usually (in glasses) a Fermi level is fixed in the middle of mobility gap $[2,8]$, one can estimate the (thermal) energy gap width as $\approx 1.5 \mathrm{eV}$. Real (traditionally determined as an optical) mobility gap width at a room temperature can be estimated taking into account a real LFCM elastic constants [9] and thermal expansion coefficient, as $1.8 \div 2 \mathrm{eV}$.

There is an additional question, connected with an origination of noticeable electron conductivity. In accordance with a conventional point of view [2], in oxide glasses having electron conductivity there are conditions for weakened manifestation of the tendencies typical of transient metal oxides. As far as pure transient metal oxides have no tendency to vitrification, the usual way to obtain noticeable electron conductivity is to add them into a glassy composition. The electron conductivity does depend on concentration of cations having uncompleted d-shells. There are well-known oxide glassy compositions, containing $\mathrm{Ti}^{4+}$ and $\mathrm{V}^{4+}$; noticeable electron conductivity has in fact been observed for glasses containing Fe, Co and Mn oxides. In our case, at the first glance, one can suggest that Fe and $\mathrm{U}$ ions (see table 1), having uncompleted d-shells, can provide a domination of free electrons in hightemperature conductivity regarding simultaneous blocking of ion hopping transport by $\mathrm{Ca}^{++}$and $\mathrm{Mg}^{++}$ions.

Let us estimate an order of electron conductivity value. As far as electron transport is provided through extended states of conduction band, which are not far from a mobility edge, the extreme disorder of electron scattering takes place, where between any two acts of scattering the phase coherence of electron wave turned out to be lost. In this case, according to Mott $[8,10]$ one may expect that pre-exponent 
coefficient $\rho_{0}$ will correspond to the minimum metallic conductivity quantity

$$
\sigma_{\min }=\frac{A e^{2}}{\hbar \delta},
$$

where $A$ is the numerical coefficient being 0.026 , if coordination number is 6 and vertical disorder dominates; $\delta$ is the average distance between impurity centres being $\approx 0.5539 N^{-1 / 3}$ in a case of their random spatial distribution. Here $N$ is their concentration. One can find from figure 5 data that $\rho_{0}^{-1}=\sigma_{0} \approx 20 \Omega^{-1} m^{-1}$. This value, however, is smaller, than a typical one for both glasses having electron conductivity [2] and amorphous semiconductors [8]. If one compares that value with (4) relation, it will give $N \approx 10^{13} \mathrm{~cm}^{-3}$, which is a very small value. Such a small $N$ value can be explained by self-compensation phenomena, which are frequently observable in semiconductors having deep captures (for example, vacancies and interstitial atoms) [14]. Another approach based on the consideration that the typical drift mobility value $\mu$ for glasses, when extended states transport occurs (near a mobility edge), is of the order of $1 \mathrm{~cm}^{2} / V \cdot s$. Then, taking into account that $\sigma_{0}=N e \mu$, one can obtain $N \approx 10^{18} \mathrm{~cm}^{-3}$, which is more reasonable and provide the density of states $(T=550 \mathrm{~K})$ about $2 \cdot 10^{19} \mathrm{~cm}^{-3} \mathrm{eV}^{-1}$.

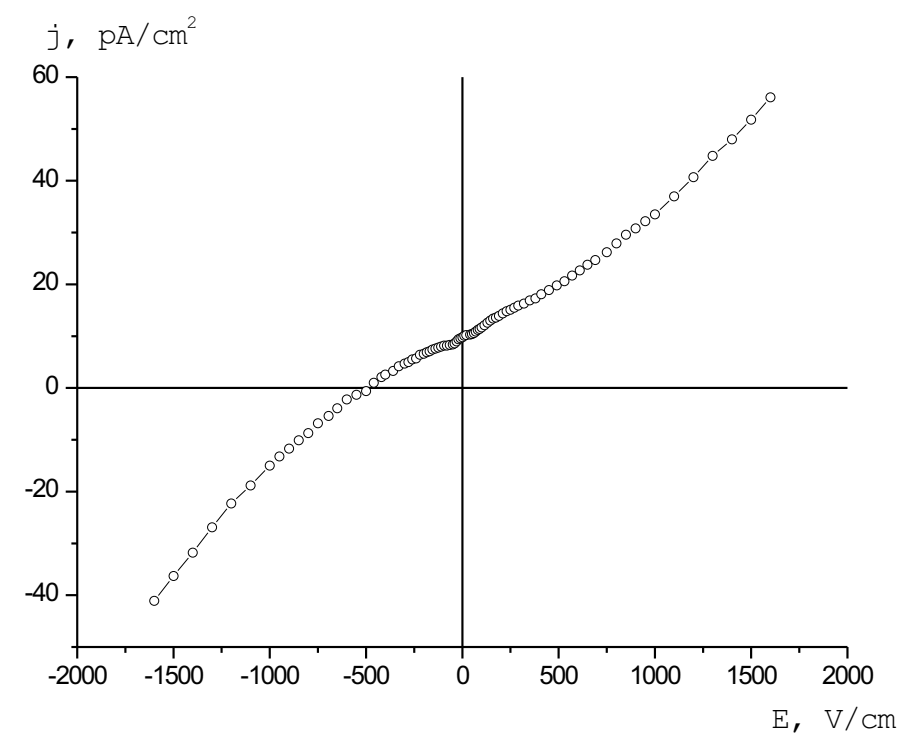

Figure 7. LFCM volt-ampere characteristic at $T=294 \mathrm{~K}$. One can identify non-ohmic regime connected with hopping conductivity in the band tails.

As one can identify from figure 5 , at $T<350 \mathrm{~K}$ we do have another conductivity mechanism. In the temperature interval $350 \mathrm{~K}<T<270 \mathrm{~K}$ it can be described by the activation law

$$
\rho(T)=\rho_{2} \exp \left(E_{2} / k T\right),
$$

where the corresponding activation energy is $0,47 \mathrm{eV}$. The pre-exponent coefficient for conductivity is three-orders smaller than $\sigma_{0}$ value, which points indirectly to the 
conductivity mechanism through localized states. It is a well-known mechanism for numerous glasses and amorphous semiconductors, when activation occurs from the Fermi level to the localized states belonging to a conduction (and valence) band tails. A conventional convincing proof for such conductivity mechanism is a noticeable conductivity increase even in moderate electric fields. There was measured the volt-ampere characteristic at $T=294 \mathrm{~K}$, which belongs to the above temperature interval. Results are presented in figure 7.

One can see in figure 7 a noticeable deviation of the presented characteristic from linear law since $\approx 500 \mathrm{~V} / \mathrm{cm}$. The deviation corresponds to non-ohmic hopping conductivity regime on localized states belonging to the conduction band tail and become sufficient when $e E R \approx k T$, where $R$ is the hopping range. Rough estimation from figure 7 data provides $R \approx 250 \mathrm{~nm}$. In order to identify the physical sense of such $R$ value, one should estimate the density of localized states in the band tail located in the energy interval between $0.47 \mathrm{eV}$ and $0.74 \mathrm{eV}$. Considering that the band tail width is $\Delta E \approx E_{1}-E_{2} \approx 0.27 \mathrm{eV}$, which is connected with Coulomb interaction between neighbouring localized states, one can use the known relation, which is commonly used for impurity band in semiconductors [11], namely

$$
\Delta E \approx \frac{e^{2} N^{1 / 3}}{4 \pi \varepsilon_{0} \varepsilon},
$$

where $N$ is the localised state concentration, $\varepsilon_{0}$ and $\varepsilon$ are the dielectric constant and LFCM dielectric permeability, correspondingly. Taking into account $\varepsilon \approx 10$ for LFCM [12], one can establish from $(6)$ the $N \approx 2 \cdot 10^{22} \mathrm{~cm}^{-3}$ and the corresponding density of states will be about $8 \cdot 10^{22} \mathrm{~cm}^{-3} \mathrm{eV}^{-1}$. These are the upper-limit estimations as far $\Delta E$ may be increased due to compensation processes [11], but no doubt the order of values is correct. The average distance between neighbouring localized states will be $\delta \approx 3 \mathrm{~nm}$ at the above concentration. One can conclude hear that the above mentioned hopping range of $250 \mathrm{~nm}$ corresponds to the variable range hopping regime in the band tail transport, but proper temperature dependence cannot be observed while $E_{2}$ activation mechanism prevails.

At $T<270 \mathrm{~K}$ the $E_{2}$ - conductivity mechanism is exhausted and activation energy decays with temperature lowering. Data processing for $270 \mathrm{~K}<T<80 \mathrm{~K}$ temperature region shows that $\rho(T)$ dependence obeys the well-known Mott law

$$
\rho(T)=\rho_{m} \exp \left[\left(\frac{T_{0}}{T}\right)^{1 / 4}\right],
$$

where $T_{0}$ is the parameter, which depends on localized states overlapping. The results are presented in figure 8 .

One can detect from this figure that (7) dependence covers more than three orders of $\rho(T)$ value. From the straight line slope it is possible to determine $T_{0} \approx 4 \cdot 10^{7} \mathrm{~K}$ value. No doubt, this is a variable range hopping process, which occurs in a narrow band of the order of $\mathrm{kT}$ width in the Fermi level vicinity. There were provided special calculations for $T_{0}$ value $[8,11,13]$ based on percolation approach. Those calculations 


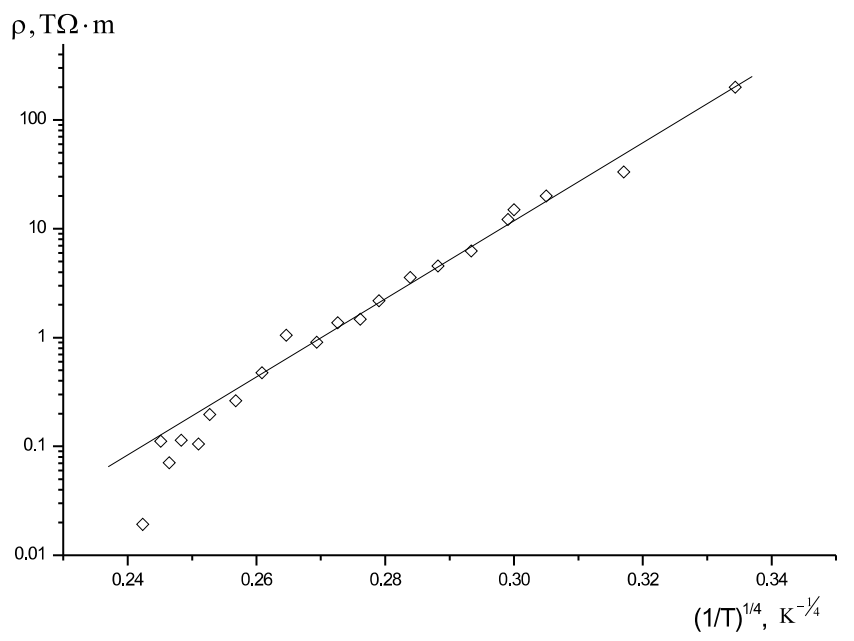

Figure 8. Dependence of low-temperature LFCM specific resistance on temperature. VRH-regime indicated by the straight line.

give the similar result, which is

$$
T_{0} \approx(16.9 \div 17.5) \frac{\gamma^{3}}{N\left(E_{\mathrm{F}}\right)}
$$

where $\gamma^{-1}$ is the localization radii for screened Coulomb potential of $\exp (-\gamma r)$ type, $N\left(E_{\mathrm{F}}\right)$ is the density of localized states on the Fermi level and numerical coefficient in the round brackets originates from percolation considerations. Then, if we suggest $\gamma^{-1} \approx 0.5 \mathrm{~nm}$ as a reasonable value for numerous amorphous semiconductors and oxide glasses [13], one can establish from (8) relation, taking into account the experimental $T_{0}$ value, that $N\left(E_{\mathrm{F}}\right) \approx 2 \cdot 10^{19} \mathrm{~cm}^{-3} \mathrm{eV}^{-1}$. At last, let us give the rough lower-value estimation for possible energy width for the stripe of localized states on the Fermi level. Thorough calculation of proper percolation problem [11], we can estimate an upper temperature edge; below that edge the conductivity mechanism (7) should dominate. That estimation gives

$$
k T_{\mathrm{c}} \approx 0.3 \cdot \Delta E_{\mathrm{f}}
$$

where $\Delta E_{\mathrm{f}}$ is the energy width and $T_{\mathrm{c}}$ is the corresponding temperature edge. One can easily identify from figure 8 data that $T_{\mathrm{c}} \approx 260 \mathrm{~K}$, so one can obtain from (9) the $\Delta E_{\mathrm{f}}>0.07 \mathrm{eV}$. In the case of classical gapless glasses, where the mobility edges exist only, one should expect (at $T>T_{\mathrm{c}}$ ) the hopping process with low activation energy (of the order of $0.1 \mathrm{eV}$ ) observation, connected with nearest-neighbour hopping (usual $\varepsilon_{3}$-conductivity [11]). We can observe, however, the $E_{2}$ value only, which is not in coincidence with expected hypothetic $\varepsilon_{3}$ one. There is one distinct physical explanation for such divergence - the localized states having $E>E_{2}$ energy and the ones situated just near the Fermi level simply belong to the different bands of localized states. It means, that the density of states between $E_{2}$ and the Fermi level (except $\Delta E_{\mathrm{f}}$ ) is close to zero, i.e. that the real energy gap does exist between them. 
Finally, the lowest estimation for localized states on the Fermi level concentration will be (one may consider $N\left(E_{\mathrm{F}}\right)$ to be practically constant regarding the good obeying of figure 8 experimental data to the $(7)$ law) the $N\left(E_{\mathrm{F}}\right) \cdot \Delta E_{\mathrm{f}} \approx 1.5 \cdot 10^{18} \mathrm{~cm}^{-3}$ value.

\section{Conclusions}

The heap of the above described experimental results makes it possible to determine preliminaryly the LFCM energy structure and, hence, to classify it as a condensed matter sort. The suggested LFCM energy structure is presented in figure 9 .

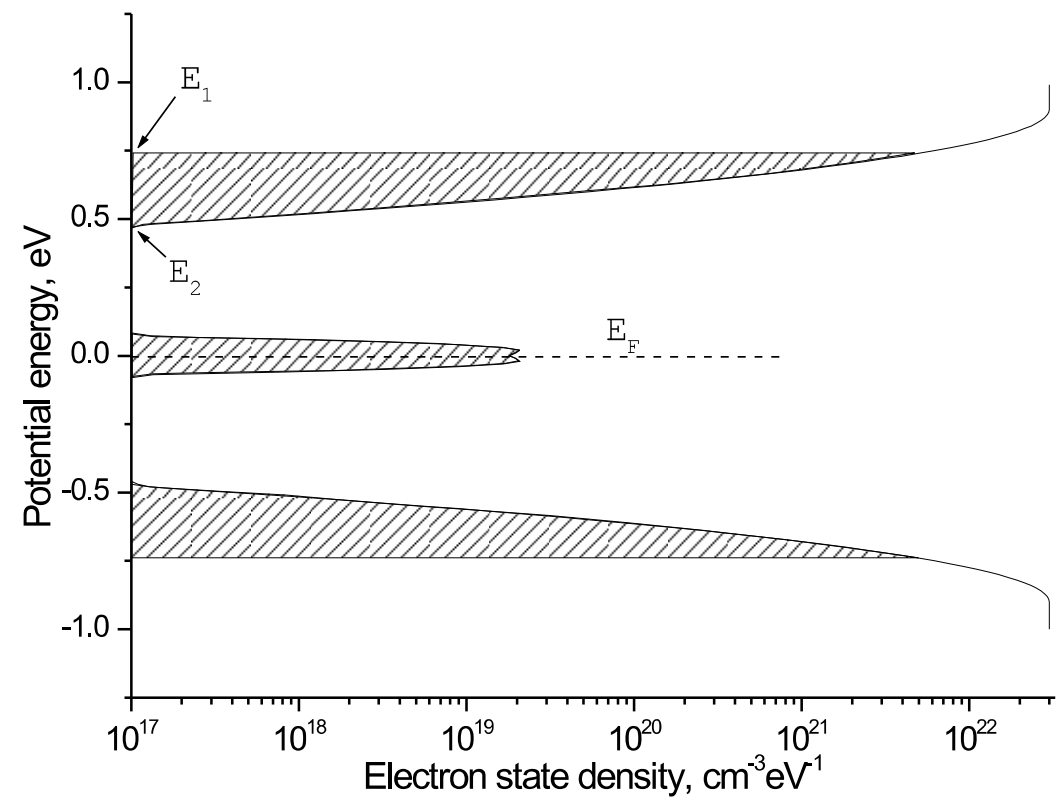

Figure 9. Suggested LFCM energy structure. Localized states are identified by the dashed area.

The main outcomes are as follows:

1. LFCM are the alkali-earth silicate glasses, whose vitrification temperature belongs to $1000 \mathrm{~K} \div 1100 \mathrm{~K}$ temperature interval.

2. LFCM is an disordered semiconductor having an energy gap which formed due to a short-range order and a wide band tails connected, as it is common for glasses, with horizontal disordering (see figure 9), which, in its turn, may be connected with numerous traps and radiation damages. Estimated thermal energy gap is $1.5 \mathrm{eV}$, possible optical energy gap at a room temperature is $1.8 \div 2.0 \mathrm{eV}$. There is a noticeable concentration of localized states just on a Fermi level.

3. There are no evidences for ionic transport, which can be explained by its blocking by alkali-earth ions, such as $\mathrm{Ca}^{++}$and $\mathrm{Mg}^{++}$. At $1000 \mathrm{~K}<T<$ 
$350 \mathrm{~K}$ the main mechanism responsible for electric transport is a thermal activation of electrons on the mobility edge $E_{1}$. Such type of conductivity (pre-exponent coefficient $\sigma_{0}$ value) is anomalously low, which can be explained by self-compensation processes. Another possible factor for it might be a nonequilibrium energy spectrum for free electrons in a conduction band originated from fast $\beta$-electrons and a great amount of secondary electrons, which leads to chaotization of free electrons movement and prevents their directed movement along the external electric field. At $350 \mathrm{~K}<T<270 \mathrm{~K}$ an electric transport is provided by hopping conductivity in the band tails, whose energy threshold is $E_{2}$. The high localized states density can be provided by $\mathrm{U}^{4+}$ and $\mathrm{Fe}^{3+}$ ions, having changeable valence, whose concentration is about $1 \%$ (atomic). At $T<260 \mathrm{~K}$ the variable range hopping in a stripe of order $\mathrm{kT}$ around a Fermi level was identified as the dominating mechanism.

4. An internal irradiation process leads to the appearance of self-sustained currents; observable external current corresponds to internal radioactivity, as far as a surface Coulomb barrier for secondary electrons exists. Such a barrier can be destroyed by heating due to electric conductivity enlarging, which results in the involvement of secondary electrons in electric transport. The thermalstimulated current, connected with traps liberation can be also observed at a fast heating. Spontaneous electric fields, connected with internal currents, can also be observed. Their strength achieves $1 \mathrm{kV} / \mathrm{cm}$ and more at a room temperature.

5. The distinguishing feature of LFCM is low activation energy for electron ionization, which can provide a high spatial density of electron excitations in $\alpha$-particles tracks and can lead to the group of phenomena, connected with the so-called Coulomb explosion. The latter item is a subject of a special interest $[14,15]$.

\section{References}

1. Pazukhin E.M. Lava-like Fuel-containing masses of the Unit 4 of Chornobyl NPP: Physical and Chemical Properties, Formation Scenario, Impact on the Environment (in Russian). Thesis for doctor's degree in engineering sciences, ISTC "Shelter" NASU, Chornobyl, 1997.

2. Feltz A. Amorphe und Anorganische Festkrper. Berlin, Akademie-Verlag, 1983.

3. Baryakhtar V., Gonchar V., Zhidkov A., Zhydkov V. // Condens. Matter Phys., 2002, vol. 5, No. 3(31), p.449-471.

4. Gonchar V.V., Zhidkov A.V., Maslov D.M. Electron emission from LFCM surface and qualitative picture for electric field distribution in its near-surface layer. // Problems of Chornobyl, 2004, vol. 14, (in Ukrainian).

5. Bronstein I.M., Fraiman B.S. Secondary Electron Emission, (in Russian). Moskow, Nauka, 1969. 
6. Alexankin V.G., Rodichev S.V., Rubtsov P.M. et al. Beta- and Antineutrinic Radiation of Radioactive Nuclei, (in Russian). Reference book. Moscow, Energoatomizdat, p. $800,1989$.

7. Milnes A.G. Deep Impurities in Semiconductors. New York, John Wiley \& Sons, 1977.

8. Mott N.F., Davis E.A. Electron Processes in Non-Crystalline Materials. Oxford, Clarendon press, 1979.

9. Zhydkov V., Chemersky G. Lava-like fuel-containing materials dynamic elastic constants determination in the workbench. (in Ukrainian) // Problems of Chornobyl, 2004, vol. 14.

10. Mott N.F. Metal-Insulator Transitions. London, Taylor and Francis LTD, 1974.

11. Shklovskii B.I., Efros A.L. Electronic Properties of Doped Semiconductors. Springer, 1983.

12. Zhydkov O. (supervisor) et al. Fuel-Containing Materials Electrodynamics Properties Study when Creating the Technology for its Separation from other "Shelter" Object Radioactive Waste, (in Ukrainian). Annual Research Report of Interdisciplinary Scientific and Technical Centre "Shelter". Chornobyl, Government issue 0101U002570, 2003.

13. Bonch-Bruevich V.L. et al. Electron Theory for Disordered Semiconductors, (in Russian). Moscow, Nauka, 1981.

14. Baryakhtar V.G., ed. Solid State Physics (Encyclopaedia dictionary), (in Russian). Kiev, 1998.

15. Zhydkov V. Coulomb explosion and steadiness of high-radioactive silicate glasses. // Condens. Matter Phys., 2004, vol. 7, No. 4, p. 845. 


\section{Електронний та іонний транспорт в високорадіоактивних силікатних лужноземельних стеклах}

\section{О.В.Жидков}

Інститут Проблем Безпеки АЕС НАН України

Отримано 16 серпня 2004 р., в остаточному вигляді 20 серпня 2004 р.

Робота присвячена експериментальному вивченню електроперенесення в дуже особливій речовині, а саме в лужноземельних стеклах, що містять помітну кількість (до 10\%) розчиненого опроміненого ядерного палива та продуктів його поділу і напрацьованих продуктів. Такий високорадіоактивний матеріал був сформований в перебігу активної фази загальновідомої тяжкої ядерної аварії, що відбулася на Чорнобильській AEC 1986 року. Поведінку такої речовини як електроліту було вивчено шляхом вимірювання температурної залежності в'язкості, при цьому недвозначно було ідентифіковано властивості, характерні для стекол. Було виміряно температурну залежність статичної електропровідності в інтервалі температур 80 K-1000 К. Було ідентифіковано процеси перенесення шляхом термічної активації електронів, стрибкову провідність в хвостах зон та стрибкову провідність зі змінною довжиною стрибка. Зонна структура таких стекол виявляє наявність забороненої зони шириною 1.8-2.0 еВ, сформованої через наявність дальнього порядку, та широких хвостів зон через горизонтальний безлад, який, в свою чергу, може бути зумовлений численними пастками та радіаційними дефектами. Останнє дозволяє ідентифікувати досліджений матеріал як ситал. Визначною особливістю таких ситалів є низька енергія іонізації для електронів, що забезпечує значну просторову густину електронних збуджень в треках $\alpha$-часток і спричиняє прояв такого колективного явища, як кулонівський вибух.

Ключові слова: кераміка, радіоактивні стекла, стрибкова провідність

PACS: 72.20.Ee, 71.20.Dg 